\title{
Cue reactivity and regulation of food intake.
}

Citation for published version (APA):

Nederkoorn, C., \& Jansen, A. T. M. (2002). Cue reactivity and regulation of food intake. Eating Behaviors, 3, 61-72. https://doi.org/10.1016/S1471-0153(01)00045-9

Document status and date:

Published: 01/01/2002

DOI:

10.1016/S1471-0153(01)00045-9

Document Version:

Publisher's PDF, also known as Version of record

\section{Document license:}

Taverne

\section{Please check the document version of this publication:}

- A submitted manuscript is the version of the article upon submission and before peer-review. There can be important differences between the submitted version and the official published version of record.

People interested in the research are advised to contact the author for the final version of the publication, or visit the DOI to the publisher's website.

- The final author version and the galley proof are versions of the publication after peer review.

- The final published version features the final layout of the paper including the volume, issue and page numbers.

Link to publication

\footnotetext{
General rights rights.

- You may freely distribute the URL identifying the publication in the public portal. please follow below link for the End User Agreement:

www.umlib.nl/taverne-license

Take down policy

If you believe that this document breaches copyright please contact us at:

repository@maastrichtuniversity.nl

providing details and we will investigate your claim.
}

Copyright and moral rights for the publications made accessible in the public portal are retained by the authors and/or other copyright owners and it is a condition of accessing publications that users recognise and abide by the legal requirements associated with these

- Users may download and print one copy of any publication from the public portal for the purpose of private study or research.

- You may not further distribute the material or use it for any profit-making activity or commercial gain

If the publication is distributed under the terms of Article $25 \mathrm{fa}$ of the Dutch Copyright Act, indicated by the "Taverne" license above, 


\title{
Cue reactivity and regulation of food intake
}

\author{
Chantal Nederkoorn*, Anita Jansen \\ Department of Experimental Psychology, Maastricht University, PO Box 616, \\ Maastricht 6200 MD, The Netherlands
}

\begin{abstract}
A robust finding in eating research is the so-called counterregulation in restrained eaters. This means that while normal subjects eat less during a taste test, after they consumed a preload, restrained eaters consume more. An explanation is that food exposure causes stronger physiological preparatory reactivity in the restrained eaters. This reactivity is experienced as craving and leads to an increased food intake. To test this theory, 46 high and low restrained eaters were exposed to food or soap, while physiological measurements were made. Afterwards, the subjects performed a taste test, during which food intake was secretly measured. Unrestrained eaters showed an increase in heart rate, gastric activity, and saliva during food exposure; however, restrained eaters did not. Gastric activity significantly correlated with food intake. Group or exposure type did not influence food intake. It can be concluded that unrestrained eaters prepared for food intake, whereas the restrained eaters did not. A possible explanation is that restrained eaters used cognitive suppression to block physiological responding, thereby controlling their food intake. (C) 2001 Elsevier Science Ltd. All rights reserved.
\end{abstract}

Keywords: Binge eating; Restrained eating; Conditioning; Cue reactivity

\section{Introduction}

A large group of people is struggling with their food intake, trying to restrict it, but often fail to do so. Herman and Mack (1975) performed an elegant experiment, using the so-called preload paradigm, in which this phenomenon is shown. In that experiment, unrestrained eaters showed normal regulation of their eating behavior; after they ate a preload (milkshake), they ate less ice cream during a subsequent taste test than when they ate no preload. Restrained eaters,

* Corresponding author. Tel.: +31-43-388-1925/1908; fax: +31-43-361-5735.

E-mail address: c.nederkoorn@psychology.unimaas.nl (C. Nederkoorn). 
however, defined as subjects who want to restrict their food intake, consumed less during a taste test when they did not eat a preload, but they consumed more during the taste test when they did eat a preload. This illogical behavior is called counterregulation and Herman and Mack's experiment initiated a large body of research. Restrained eaters repeatedly showed abnormal regulation of food intake (for an overview, see Boon, 1998). How can this eating pattern of restrained eaters be explained? A widespread cognitive explanation stems from the boundary model (Herman \& Polivy, 1984). In this model, biological boundaries determine when a person feels hungry or satiated and thereby when a person starts and stops eating. Restrained eaters have another self-imposed boundary, marking their maximum desired consumption, the socalled diet boundary. As long as this boundary is not broken, the restrained eater succeeds in restricting food intake. When this diet boundary is broken, for example, after eating the preload, restrained eaters have disinhibitory thoughts, like "I've already blown my diet, I might as well continue to eat," and start overeating. However, restrained eaters also showed abnormal regulation after exposure to the sight, smell, or thought of food, without actually eating it (Fedoroff, Polivy, \& Herman, 1997; Jansen \& Van den Hout, 1991). These findings cannot be explained with the disinhibitive thoughts of the boundary model; the "preload" was not consumed, and, thus, no diet rule was broken. Furthermore, no evidence of disinhibitive thoughts was found when restrained eaters were instructed to think aloud during the preload condition (Jansen, Merckelbach, Oosterlaan, Tuiten, \& van den Hout, 1988).

An alternative explanation for the counterregulation phenomenon stems from the cue reactivity theory. This theory states that when a person regularly has eating binges, and these binges are reliable preceded by certain cues (e.g., the sight, smell and taste of the food, environment, cognitions, and emotions), these cues become predictors of the start of a binge. Exposure to these cues induces conditioned physiological reactivity, which can prepare the person for the intake of food. In normal subjects, physiological responses to food cues are widely documented and called cephalic phase responses (Mattes, 1997; Nederkoorn, Smulders, \& Jansen, 2000). Binge eaters are expected to show even larger cephalic phase responses because the enormous amount of food intake during a binge threatens the homeostatic balances of the body, and anticipation is more important compared to normal food intake. In addition, more intense unconditioned stimulus, in this case the food intake, strengthens the conditioning. The cue reactivity is experienced as craving for the food and triggers an eating binge (Jansen, 1994, 1998; Wardle, 1990). The theory originates in the addiction field, where increased psychophysiological reactivity and craving are found when the substance abuser is exposed to drug/alcohol cues (Glautier \& Remington, 1995; Robbins, Ehrman, Childress, \& O'Brien, 1997), and studies suggest that craving for a substance is a classical conditioned response (Drummond, Tiffany, Glautier, \& Remington, 1995). At least a part of the restrained eaters shows an eating pattern of dieting and overeating, which resembles the eating pattern of subjects with eating binges. Applied to the preload paradigm, the cue reactivity model of binge eating states that exposure to a preload, either by seeing and smelling or actually eating it, will elicit conditioned physiological responses and craving in the restrained eater. This, in turn, leads to increased food intake and counterregulation. From the model, it also follows that, when not exposed to the preload or other binge cues, the restrained eater is able to control food intake and eats less. 
In sum, the cue reactivity model predicts that: (1) restrained eaters show more physiological reactivity when exposed to binge cues than unrestrained eaters. (2) Cue reactivity is experienced as craving and (3) the increased reactivity and craving during the exposure lead to increases in the food intake of the restrained eaters during the taste test afterwards. Furthermore, the cognitive theory on overeating predicts that (4) a preload (or exposure to "forbidden" food) elicits disinhibitive thoughts in restrained eaters, which lead to an increased food intake during the taste test.

The present experiment was designed to test these four hypotheses. Restrained and unrestrained women participated in an adjusted "preload" experiment, in which half of them was exposed to the sight and smell of food, without consuming it, and the other half was exposed to control stimuli. During the exposure, physiological reactivity was measured. Before and after the exposure, the subjects rated several subjective states, like craving for food. Afterwards, the participants performed a taste test and food intake was measured. At the end, the subjects rated retrospectively the frequency of disinhibitory thoughts during the exposure period.

\section{Methods}

\subsection{Participants}

As part of another study, first year students of psychology and health sciences of Maastricht University were invited to complete a set of questionnaires, among which is a Dutch translation of the White Bear Suppression Inventory (WBSI; Wegner \& Zanakos, 1994) and the Restraint Scale (RS; Herman \& Polivy, 1980). A total of 173 participants returned the questionnaires. Women with scores higher than 15 and lower than 10 ( $1 / 2$ standard deviation of the mean in earlier studies of the authors) on the RS were invited by telephone to participate in a smell and taste experiment. Forty-six women participated. The data of two participants were excluded from the analyses, one participant because of use of medication (Prozac) and one participant because she saw through the experimental manipulations and purpose of the study. All participants filled in the RS again directly after the experiment to obtain scores directly related to the time of the experiment. Based on the mean RS score during the experiment (11.9), 20 participants with higher scores were classified as restrained eaters and 24 participants with lower scores were classified as unrestrained eaters (mean scores are revealed in Table 1).

Table 1

Mean and standard error of age, BMI, RS, and EDE-Q for both groups

\begin{tabular}{llll}
\hline & Restrained eaters $(n=20)$ & Unrestrained eaters $(n=24)$ & Difference \\
\hline Age & $19.7(0.6)$ & $19.0(0.2)$ & $F(1,43)=1.5$, N.S. \\
BMI & $24.1(0.5)$ & $21.3(0.5)$ & $F(1,43)=14.5, P<.001$ \\
RS & $18.2(1.0)$ & $6.8(0.5)$ & $F(1,43)=114, P<.001$ \\
EDE-Q (total) & $2.3(0.3)$ & $0.6(0.1)$ & $F(1,43)=17.8, P<.001$ \\
\hline
\end{tabular}




\subsection{Measurements}

Subjective states (relaxation, hunger, anger, craving for food, anxiety, and nausea) were scored on visual analogue scales (VAS), ranging from 0 (e.g., not at all angry) to 100 (e.g., very angry).

The subjects rated the frequencies of stereotypical disinhibitory thoughts during the taste test retrospectively, ranging from 0 (not thought this at all) to 100 (thought it all the time). The disinhibitory thoughts were: "My day is ruined now, I might as well continue to eat," "I cannot control myself," "Everything must be eaten," "Stay away from the food," "I don't have myself in hand," and "I have already eaten too much now, let's take another bite." The scores were summed up to obtain an overall score.

A Dutch translation of the RS (Herman \& Polivy, 1980) was used to measure the intention to restrain food intake. Subjects scoring high on the RS are characterized by an eating pattern alternating between dieting episodes and periodic overeating (Herman \& Polivy, 1980). A Dutch translation of the EDE-Q (Fairburn \& Beglin, 1994) was used to measure to existence of specific eating psychopathology. The EDE-Q informs about restraintness, as well as eating, weight, and shape concern, and contains seven items that are not included in the sum score. One of these items asks the number of eating binges during the last 28 days. The WBSI (Wegner \& Zanakos, 1994) exists with 15 items and measures the habituational tendency to suppress unwanted thoughts. The participants also completed a questionnaire that checked compliance with the instructions and use of medication. Furthermore, the women had to describe the aim of the experiment to check whether they were conscious of the fact that the taste test was a pretext and that actually food intake measured.

Physiological measurements were all sampled with $250 \mathrm{~Hz}$. Heart rate, blood pressure, electrogastrography, salivation, skin conductance, and skin temperature were measured. Physiological measurements were made during the baseline $(4 \mathrm{~min})$ and during the exposure period $(8 \mathrm{~min})$.

Heart rate was measured by three $\mathrm{Ag}-\mathrm{AgCl}$ electrodes, two attached over the heart region and a reference electrode was placed on the left elbow. R-waves were detected offline with a template matching procedure, and beats per minute were calculated.

Blood pressure was transduced using a Finapress Monitor (Ohmeda); the Finapress cuff was attached around the middle phalanx of the middle finger of the nondominant hand. The hand was placed on a box on the table, the height of which was the same as the heart region.

Electrogastrography was measured by three $\mathrm{Ag}-\mathrm{AgCl}$ electrodes, one placed on the participant's left side approximately $6 \mathrm{~cm}$ from the midline and just below the lowest rib, another just above the umbilicus and a reference electrode placed on the participant's left elbow. The signal was off-line resampled at $25 \mathrm{~Hz}$, mean and linear trends were removed, the signal was filtered with a high pass filter (at $0.0184 \mathrm{~Hz},-3 \mathrm{~dB}$ ), and windowed with a cosine bell window (10\%). After the preprocessing, the 4-min epochs were Fourier-transformed and power was calculated in the frequency band between 2.5 and $3.5 \mathrm{cpm}$. To diminish large individual differences in scores caused by, among others, the thickness of the fat layer on the stomach, ratio scores with the baseline (exposure/baseline) were calculated. 
As a measure of salivation, swallows were recorded (Nederkoorn, Smulder, \& Jansen, 1999; Nederkoorn et al., 2000; Pomerleau, Fertig, Baker, \& Cooney, 1983). The accompanying EMG signal was recorded with three $\mathrm{Ag}-\mathrm{AgCl}$ electrodes - two electrodes were attached under the left jaw, in the length of the anterior part of the musculus digastricus, and a reference electrode was placed on the left mastoid process. Before digitization, a band pass filter was set between 10 and $300 \mathrm{~Hz}$, and the signal was rectified and integrated. The digitized epochs were low pass filtered (at $0.4 \mathrm{~Hz},-3 \mathrm{~dB}$ ) to smooth the signal. Artifacts like coughing or talking were removed, and by visual inspection of the data, the definition of a swallowing response was determined as a response of the integrated signal above a $5-\mu \mathrm{V}$ threshold, with a minimum of $1.5 \mathrm{~s}$ between responses.

Skin conductance was measured with three $\mathrm{Ag}-\mathrm{AgCl}$ electrodes placed on the thenar and hypothenar eminences of the palm of the nondominant hand; the reference electrode was placed on the back of this hand.

Temperature was measured by a thermistor, placed on the skin in the proximity of the liver. This was thought to be the most sensitive place for measuring changes in surface temperature caused by metabolic processes (Westerterp-Plantenga, Wouters, \& ten Hoor, 1990).

\subsection{Procedure}

The participants were instructed not to eat for $3 \mathrm{~h}$ before the experiment. After entering the laboratory, electrodes were attached and signals were checked. The subject was told that physiological reactivity to several odors would be measured. In front of the participant, a round table was turning, and paused for a few seconds every quarter of the plateau. The participant was instructed to sit quietly and relaxed. First, a baseline measurement of $4 \mathrm{~min}$ was made. Then the participant rated its subjective states on the VAS scales. Thereafter, four bowls were placed on the turning table, just under the nose of the participant. In the food condition, the bowls contained chocolate raisins, a kind of spice nuts (typical Dutch one-bite cookies, called "pepernoten"), cocktail nuts, and small pieces of liquorice (called "kokindjes"), respectively. In the control condition, the bowls contained four different kinds of small pieces of bath soap. All bowls were filled with large amounts of the stimuli. The participant was instructed to concentrate on the smell of the stimuli and to sit quiet and relaxed again. The exposure continued for $8 \mathrm{~min}$, during which physiological measurements were made. Then the participant rated its subjective states again on the VAS scales. The turning table was removed, and the bowls were placed on the desk, in front of the participant. The participant had to fill in a questionnaire about the smell of the four stimuli. Once the questionnaire was filled in, the taste test began. The women in both conditions received four bowls with food stimuli and a questionnaire about the taste of the food items. Subjects in the experimental group tasted the food they had smelled; subjects in the control group also tasted the food in bowls that were exactly comparable to the bowls of the experimental group. The participant was told that she could eat as much as she wanted or needed to make a proper judgement over the taste. Then the participant was left alone. Fifteen minutes later, the experimenter came back and removed 
a

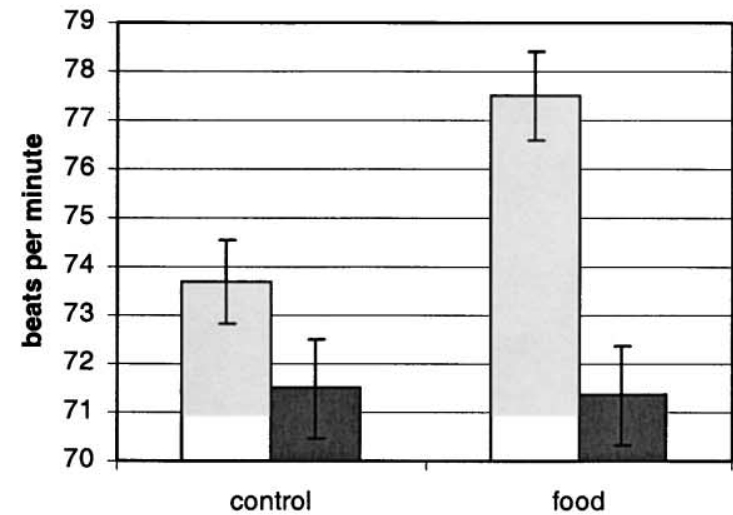

口unrestrained

口restrained

b

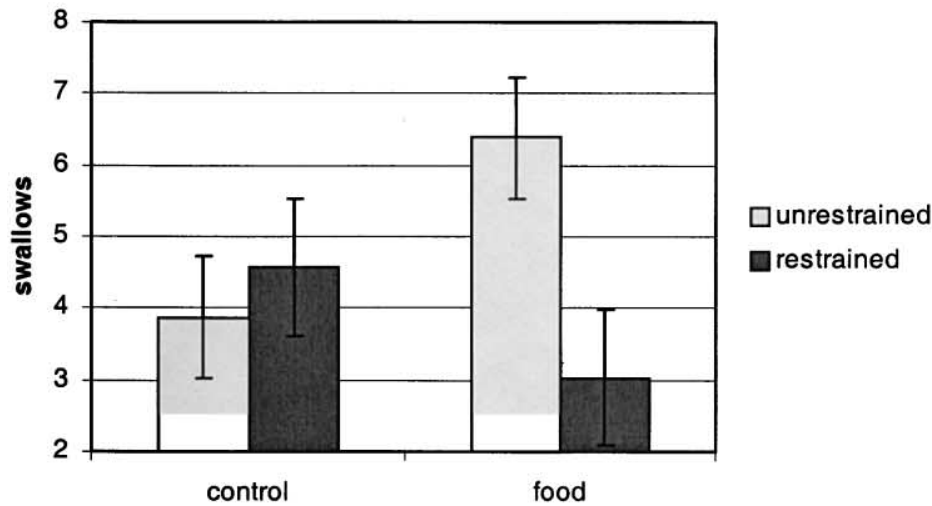

C

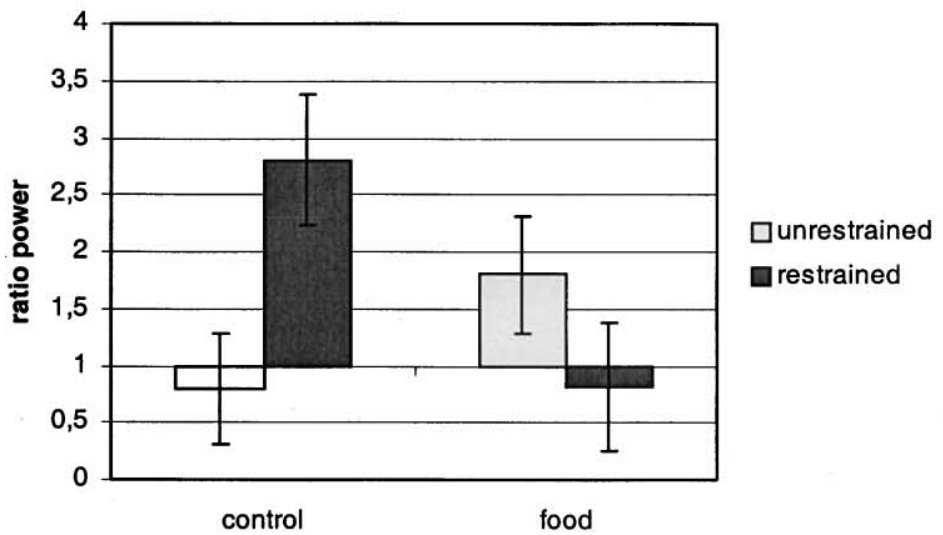

Fig. 1. Mean and standard error of heart rate (a), salivation (b), and gastric activity (c) during control and food exposure, compared to the baseline, of restrained and unrestrained eaters. 
the bowls. The participant filled in the remaining questionnaires (RS, EDE-Q, and compliance, in that order), her weight and height were measured, and she received a small grant for participation.

\subsection{Data reduction and analyses}

Mean physiological responses were calculated. Baseline scores, BMI, and time of measurement were included as covariates. All variables were analyzed using 2 (restrained/ unrestrained) $\times 2$ (food/soap exposure) between-subjects analyses of variance (ANOVA).

\section{Results}

Unrestrained and restrained eaters did not differ in age. Restrained eaters, however, had significantly higher BMI and scored higher on the RS and the EDE-Q. Mean age, BMI, and scores on the RS and EDE-Q are revealed in Table 1.

The first hypothesis of the cue reactivity theory was that:

Hypothesis 1: Restrained eaters show more reactivity to food exposure, compared to control exposure, than unrestrained eaters.

Several physiological effects were found. A significant main effect of group on heart rate emerged. The unrestrained eaters showed a higher heart rate than restrained eaters $[F(1,43)=15.9, P<.001]$. A marginal significant effect of condition was found; overall, the subjects showed a higher heart rate during food exposure than during control exposure $[F(1,43)=4.0, P=.052]$. There was also a significant interaction effect $[F(1,43)=4.1$, $P<.05]$; the heart rate of the unrestrained eaters was higher during food exposure, whereas there was no effect on the heart rate of the restrained subjects (see Fig. 1a). Gastric activity also showed a significant interaction $[F(1,43)=8.4, P<.01]$. Restrained eaters had a larger increase in gastric power during control exposure than during food exposure, whereas unrestrained eaters showed the opposite pattern (see Fig. 1b).

The same pattern was found for swallowing, restrained eaters swallowed more often during the control exposure than during food exposure; unrestrained eaters swallowed more during food exposure $[F(1,43)=5.0, P<.05]$ (see Fig. 1c).

Restrained eaters had a higher skin temperature than unrestrained eaters, irrespective of exposure type $[F(1,43)=5.9, P<.05]$. No effects were found on blood pressure (systolic, diastolic, or mean blood pressure) and skin conductance level.

The second hypothesis of the cue reactivity theory states that:

Hypothesis 2: The physiological reactivity was experienced as craving.

Both groups reported an increase in craving after food exposure compared to exposure to the control stimuli $[F(1,43)=12.3, P<.001]$. However, there was no significant correlation between any physiological measurement and craving (Fig. 2). 


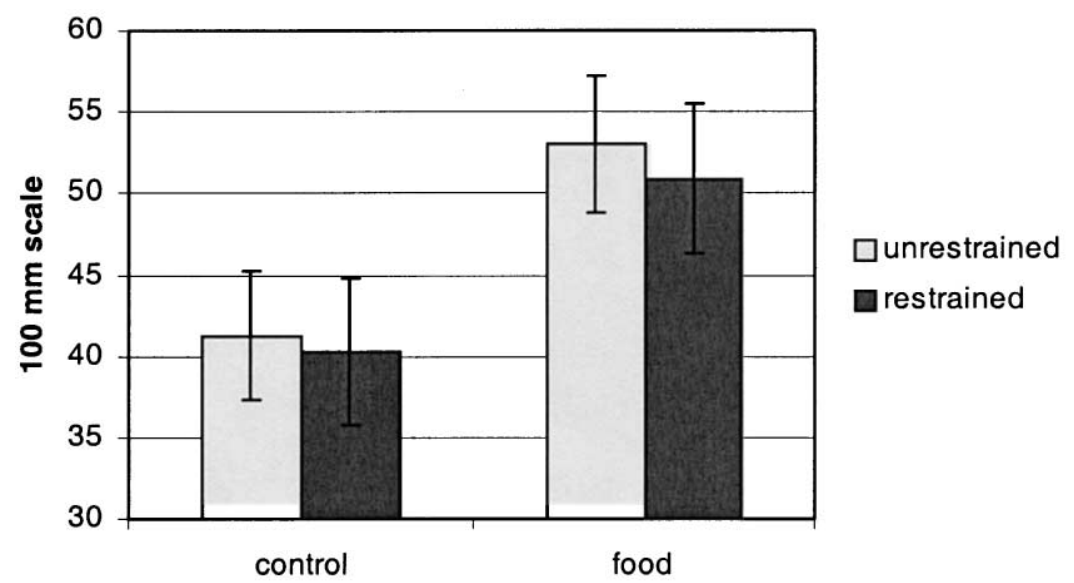

Fig. 2. Mean and standard error of the increase in reported craving after food and control exposure of restrained and unrestrained eaters.

The third hypothesis from the cue reactivity theory states that:

Hypothesis 3: An increase in cue reactivity and craving during the exposure is related to an increase in food intake during the taste test.

However, the type of exposure (control or food) did not influence food intake, in neither group. No significant difference in food intake between the groups was found. There was also no correlation between craving and food intake. Yet, there was a significant correlation between gastric activity during exposure and food intake during the taste test $(r=.39, P<.01)$. No other correlation between a physiological measurement and food intake was found. Mean kilocalories consumed during the taste test are revealed in Table 2.

The fourth hypothesis, derived from the cognitive theory, states that:

Hypothesis 4: During food exposure, restrained eaters have more disinhibitive cognitions, leading to an increased food intake during the taste test.

Retrospectively, restrained eaters indeed reported more disinhibitive cognitions than unrestrained eaters $[F(1,43)=10.2, P<.005]$; however, the cognitions were reported as frequently in the food, as well as in the control condition. No significant interaction effect

Table 2

Mean and standard error of kilocalories consumed during the taste test, by the restrained and unrestrained eaters, after control or food exposure

\begin{tabular}{lll}
\hline & Restrained eaters (kcal) & Unrestrained eaters (kcal) \\
\hline Control exposure & $324(82)$ & $408(72)$ \\
Food exposure & $227(44)$ & $300(50)$ \\
\hline
\end{tabular}


was found, and there were no significant correlations between the reported cognitions and craving for food, as well as food intake.

Exploratively, the subjective ratings of emotion (anger, fear, and relaxation) before and after the exposure were analyzed. There was a significant interaction effect on anger $[F(1,43)=4.4, P<.05]$; restrained eaters reported more anger after control exposure and less after food exposure. Unrestrained eaters reported less anger after control exposure than after food exposure. There were no significant effects of group or exposure on ratings of other subjective states (hunger and nausea). There were also no significant correlations between physiological measurements and subjective ratings.

\section{Discussion}

The aim of the present experiment was to test if the cue reactivity model explains the abnormal regulation of food intake, which is often found in restrained eaters. The theory states that restrained eaters show more reactivity when exposed to food cues (Hypothesis 1), experience this reactivity as craving (Hypothesis 2), and consequently eat more after the exposure (Hypothesis 3). Finally, the widespread cognitive model was tested, which predicts that restrained eaters have more disinhibitive thoughts during exposure to the preload and this leads to an increase in food intake (Hypothesis 4).

In respect to the first hypothesis, unrestrained eaters showed a relative larger increase in food cue reactivity than restrained eaters. Secondly, both groups reported an increase in craving after food exposure, and there was no correlation between craving, on one hand, and reactivity or food intake, on the other hand. The groups also did not differ in food intake. There was, however, a significant correlation between gastric activity and food intake.

The fourth hypothesis states that restrained eaters have more disinhibitive cognitions during food exposure, leading to counterregulation. However, the restrained eaters did report more disinhibitive cognitions than unrestrained eaters after food and control exposure. These cognitions did not lead to counterregulation and were not directly related to craving or food intake. Thus, although the restrained eaters did, in general, have more disinhibitive cognitions, they were not influenced by food exposure and unrelated to food intake.

It was thus found that unrestrained eaters showed a larger increase in cue reactivity than restrained eating subjects. How can we explain this unexpected finding? The increase in heart rate, gastric activity, and salivation in normal subjects was also found in an earlier study on cue reactivity of unrestrained eaters during food exposure (Nederkoorn et al., 2000). Now, it appears that gastric activity is indeed related to food intake. Therefore, gastric activity might be considered to reflect a preparation response for food, and interestingly, the unrestrained subjects did prepare for food intake. It was expected to find restrained eaters to show exaggerated responses. However, they showed no or decreased responses during the food exposure, compared to the control exposure. Opposite responses have also been reported by others. Karhunen, Lappalainen, Tammela, Turpeinen, and Uusitupa (1997) found a decrease in salivation in obese binge eaters during food exposure; Bulik, Lawson, and Carter (1996) found a decrease in salivation in bulimic patients during exposure to binge 
food; and Rogers, Anderson, Finch, Jas, and Gatenby (1994) found a smaller salivary increase in "chocoholics" than in controls, after exposure to chocolate. In the addiction field, it is suggested that opposite physiological reactions serve a compensatory role, thereby diminishing the effect of the drug intake (Siegel, 1989). However, normal subjects who are also conditioned on food intake prepare for food intake by increasing heart rate, gastric activity, and salivation, instead of a compensatory decrease (Mattes, 1997; Nederkoorn et al., 2000). It therefore seems unlikely that restrained eaters would show preparations responses in the opposite way.

Rogers et al. (1994) suggest that the food exposure might have caused anxiety, which could have inhibited the salivary reaction, whereas Bulik et al. (1996) found a negative relation between salivation and depression. That exposure to forbidden food can cause defense reactions is also found by Mauler, Tuschen, and Hamm (1997), who found larger startle responses in bulimic patients during food exposure. However, in our experiment, the restrained subjects did not report an increase in anxiety or anger during food exposure, nor did these emotions correlate with the physiological responses. Depression was not measured; therefore, the role of emotions cannot completely be ruled out as a determinant of physiological reactivity.

Cognitions might also have played a role of importance. Although disinhibitive cognitions were not related to physiological reactivity or food intake, cognitive strategies are able to influence physiological reactivity. Dawson and Reardon (1969) and Harvey and Wickens (1973) showed that inhibitory instructions ("It is not smart to react physiologically") can diminish the skin conductance orienting response, whereas facilitatory instructions ("It is very smart to react physiologically") enhance this response. Piacentini, Schell, and Vanderweele (1993) found that restrained eaters showed smaller orienting responses during food exposure than unrestrained eaters did. It thus might be suspected that unrestrained subjects showed physiological reactivity because they, being normal eaters, did not suppress any thought about food intake. Restrained eaters, on the other hand, are supposed to suppress eating-related cognitions. They always try to restrain their intake; in other words, it might be hypothesized that they use cognitive strategies to suppress or block their physiological reactivity. This suggestion would extant the cue reactivity theory: Food cues can elicit physiological reactivity, which leads to an increased food intake (supported by the correlation found between gastric activity and food intake), but subjects are able to inhibit these reactions by cognitive suppression. In case the suppression fails, the restrained eaters are expected to overeat. In the present experiment, the restrained eaters might have been successful in suppressing their physiological reactivity, and thereby in restraining their food intake. Indeed, we found, post hoc, a significant positive correlation between scores on the WBSI and the RS ( $r=.48, P<.001, n=43)$, suggesting that restraintness in eating and cognitive suppression, in general, are closely related. However, we did not measure suppression directly, leaving this explanation hypothetically.

Another finding in contrast to predictions of the cue reactivity model was that physiological reactivity was not related to subjective craving, and craving was not related to the amount of food intake. Of course, being in a laboratory and attached to 
physiological apparatus can have disturbed feelings of craving and inhibited food intake. It might still be possible that in natural settings, a relation will be found between craving, on one hand, and physiological reactivity and food intake, on the other hand. So far, however, we must conclude that no evidence is found that subjective craving plays a role of importance in counterregulation.

In sum, unrestrained eaters showed physiological reactivity during food exposure, and over all subjects, the gastric activity was related to the amount of food intake afterwards. There was, however, no relationship between subjective craving and food intake. Restrained eaters showed opposite physiological responses, which might result from intervening emotions or the use of cognitive strategies to suppress unwanted reactivity. Because the cognitive suppression hypothesis is post hoc and not tested in the present experiment, it might be a fruitful enterprise for further research to manipulate suppression directly during food exposure and to measure its effects on psychophysiological reactivity, as well as on food intake.

\section{Acknowledgments}

The authors acknowledge with gratitude the support of Eric Rassin with the WBSI data.

\section{References}

Boon, B. J. F. (1998). Why dieters overeat: on the cognitive regulation of eating behavior (pp. 11-43). Unpublished doctoral dissertation, University of Utrecht, the Netherlands.

Bulik, C. M., Lawson, R. H., \& Carter, F. A. (1996). Salivary reactivity in restrained and unrestrained eaters and women with bulimia nervosa. Appetite, 27, 15-24.

Dawson, M. E., \& Reardon, P. (1969). Effects of facilitatory and inhibitory sets on GSR conditioning and extinction. Journal of Experimental Psychology, 82, 462-466.

Drummond, D. C., Tiffany, S. T., Glautier, S., Remington, B. (1995). Addictive behaviour: cue exposure theory and practice. Chichester: Wiley.

Fairburn, C. G., \& Beglin, S. J. (1994). The assessment of eating disorders: interview or self-report questionnaire? International Journal of Eating Disorders, 16, 363-370.

Fedoroff, I. C., Polivy, J., \& Herman, C. P. (1997). The effect of pre exposure to food cues on the eating behavior of restrained and unrestrained eaters. Appetite, 28, 33-47.

Glautier, S., \& Remington, B. (1995). The form of responses to drug cues. In: D. C. Drummond, S. T. Tiffany, S. Glautier, \& B. Remington (Eds.), Addictive behaviour, cue exposure, theory and practice (pp. 21-46). Chichester: Wiley.

Harvey, C. B., \& Wickens, D. D. (1973). Effects of cognitive control processes on the classically conditioned galvanic skin response: a within-subjects design. Journal of Experimental Psychology, 101, 278-282.

Herman, C. P., \& Mack, D. (1975). Restrained and unrestrained eating. Journal of Personality, 43, 647-660.

Herman, C. P., \& Polivy, J. (1980). Restrained eating. In: A. B. Stunkard (Ed.), Obesity (pp. 208-255). Philadelphia, PA: Saunders.

Herman, C. P., \& Polivy, J. (1984). A boundary model for the regulation of eating. In: A. J. Stunkard, \& E. Stellar (Eds.), Eating and its disorders (pp. 141-156). New York: Raven Press.

Jansen, A. (1994). The learned nature of binge eating. In: C. R. Legg, \& D. A. Booth (Eds.), Appetite, (8, pp. 193-211). Oxford: Oxford University Press. 
Jansen, A. (1998). A learning model of binge eating: cue reactivity and cue exposure. Behaviour Research and Therapy, 36, 257-272.

Jansen, A., Merckelbach, H., Oosterlaan, J., Tuiten, A., \& van den Hout, M. A. (1988). Cognitions and self-talk during food intake of restrained and unrestrained eaters. Behaviour Research and Therapy, 26, 393-398.

Jansen, A., \& Van den Hout, M. (1991). On being led into temptation: "counterregulation" of dieters after smelling a "preload". Addictive Behaviors, 16, 247-253.

Karhunen, L. J., Lappalainen, R. I., Tammela, L., Turpeinen, A. K., \& Uusitupa, M. I. J. A. D. (1997). Subjective and physiological cephalic phase responses to food in obese binge eating women. International Journal of Eating Disorders, 21, 321-328.

Mattes, R. D. (1997). Physiological responses to sensory stimulation by food: nutritional implications. Journal of the American Dietetic Association, 97, 406-410.

Mauler, B., Tuschen, B., \& Hamm, A. (1997). Fear or craving: startle reflex modulation during viewing of food cues in deprived and nondeprived bulimics. Psychophysiology, 34, S1, S62.

Nederkoorn, C., Smulder, F. T. Y., \& Jansen, A. (1999). Recording of swallowing events using electromyography as a non-invasive measurement of salivation. Appetite, 33, 361-369.

Nederkoorn, C., Smulders, F. T. Y., \& Jansen, A. (2000). Cephalic phase responses, craving and food intake in normal subjects. Appetite, 35, 45-55.

Piacentini, A., Schell, A. M., \& Vanderweele, D. A. (1993). Restrained and nonrestrained eaters' orienting responses to food and nonfood odors. Physiology \& Behavior, 53, 133-138.

Pomerleau, O. F., Fertig, J. B., Baker, L., \& Cooney, N. (1983). Reactivity to alcohol cues in alcoholics and nonalcoholics: implications for a stimulus control analysis of drinking. Addictive Behaviors, 8 (1), 1-10.

Robbins, S. J., Ehrman, R. N., Childress, A. R., \& O'Brien, C. P. (1997). Relationships among physiological and self-report responses produced by cocaine-related cues. Addictive Behaviors, 22, 157-167.

Rogers, P., Anderson, A., Finch, G., Jas, P., \& Gatenby, S. (1994, August). Relationship between food craving and anticipatory salivation, eating patterns, mood and body weight in women and men. Poster session presented at the Society for the Study of Ingestive Behaviour, Second Independent Meeting, MacMaster University, Hamilton, Canada.

Siegel, S. (1989). Pharmacological conditioning and drug effects. In: A. J. Goudie, \& M. W. Emmett-Oglesby (Eds.), Psychoactive drugs: tolerance and sensitization (pp. 115-180). Clifton, NJ: Humana Press.

Wardle, J. (1990). Conditioning processes and cue exposure in the modification of excessive eating. Addictive Behaviors, 15 (4), 387-393.

Wegner, D. M., \& Zanakos, S. (1994). Chronic thought suppression. Journal of Personality, 62, 615-640.

Westerterp Plantenga, M. S., Wouters, L., \& ten Hoor, F. (1990). Deceleration in cumulative food intake curves, changes in body temperature and diet-induced thermogenesis. Physiology \& Behavior, 48 (6), 831-836. 